\title{
Link between the CSF shunt and achievement in adults with spina bifida
}

\author{
Gillian M Hunt, Pippa Oakeshott, Sally Kerry
}

\begin{abstract}
Objectives-A few enterprising adults with shunt treated spina bifida live independently in the community, have a job in competitive employment, and drive to work in their own car. By contrast others with similar disability but lacking their motivation remain dependent on care and supervision. The aim of this study was to identify events in the history of their shunt which may have influenced their subsequent achievement.
\end{abstract}

Methods-Between June 1963 and January 1971117 babies born in East Anglia with open spina bifida had their backs closed regardless of the severity of their condition. When reviewed in 1997 every case was ascertained. Sixty had died and the $\mathbf{5 7}$ survivors had a mean age of 30 . These were assigned to two groups: achievers and non-achievers, according to their attainments in independence, employment, and use of a car.

Results-Of the 57 survivors nine had no shunt and eight of these were achievers. All were of normal intelligence $(I Q \geqslant 80)$ and only one was severely disabled. Of the 48 with shunts only 20 were achievers (OR $11.2,95 \%$ confidence interval (95\% CI) 1.3-96.8). Lack of achievement in these 48 was associated with revisions of the shunt, particularly when revisions were performed after the age of 2 . Sixteen patients had never required a revision and 11 $(69 \%)$ were achievers; 10 had had revisions only during infancy and five (50\%) were achievers; 22 had had revisions after their second birthday and only four $(18 \%)$ were achievers $(p<0.001)$. Elective revisions were not performed in this cohort and in $75 \%$ of patients revisions had been preceded by clear symptoms of raised intracranial pressure.

Conclusion-Revisions of the shunt, particularly after the age of 2 , are associated with poor long term achievement in adults with spina bifida.

(F Neurol Neurosurg Psychiatry 1999;67:591-595)

Keywords: adults with spina bifida; achievement; cerebrospinal fluid shunts

The invention of the CSF shunt in the 1950s saved the lives of many hundreds of babies with spina bifida. However, when the results were reviewed by Laurence in 1974 he noted that the surviving children had a lower intelligence and greater disability than those few cases who had survived in the years before the shunt was available. ${ }^{1}$ As the children grew older their physical and intellectual disabilities became more evident and initial optimism waned. The value of treatment was even questioned. ${ }^{2}{ }^{3}$ Although a few children grew up into independent adults, many failed to achieve their expected potential. The ones who had never needed a shunt were generally less disabled and of normal intelligence. ${ }^{4-6}$ In those with a shunt there was a widespread belief that normal intelligence could be assured if the shunt functioned satisfactorily ${ }^{7}$ and in some centres blocked shunts were revised for this purpose even when patients were asymptomatic.

In 1963 paediatricians in East Anglia agreed to refer all newborn babies with spina bifida to the Regional Neurosurgical Unit at Addenbrooke's Hospital, Cambridge. If the parents agreed, the babies were treated without any attempt at selection. Results were to be reviewed at the end of a trial period. Before closure of the back each baby had a full neurological examination, which was carefully documented. From June 1963 until January 1971, 117 babies had their backs closed. To minimise the risk of infection the back was closed promptly, within 24 hours of birth in 108 babies (92\%) and between 24 and 48 hours in nine. Babies who presented with totally skin covered lesions were deferred for treatment and are not included in this study. At operation the open lesion was found to be a simple meningocele in four babies. In 95 babies a Pudenz-Heyer ventriculoatrial CSF shunt was inserted.

The cohort exemplifies non-selective treatment as carried out in the United Kingdom. in the 1960 s. $^{12}$ It has previously been reviewed four times by one of us $(\mathrm{GMH})$. The first review was conducted in 1971 and the outcome of treatment was assessed by home visits. ${ }^{8}$ The children were examined again aged five to 12 years when all were attending school and a formal IQ score was obtained. ${ }^{9}$ They were reviewed again in 1985 and $1992 .^{10}{ }^{11}$

All the children without shunts survived after infancy. They were of normal intelligence (defined as $I Q \geqslant 80$ ) and all but one achieved independence. The exception was the only person in this group who was severely disabled. The outcome for patients with shunts was less predictable, with some notable discrepancies. A few severely disabled subjects with shunts made remarkable achievements, unlike others who were less disabled and of normal intelligence. It was this discrepancy which prompted the present study to see if there was a relation between events in the history of the shunt and their achievement at the age of 30 . 
Table 1 Achievement and the CSF shunt in 57 patients with spina bifida (mean age 30)

\begin{tabular}{lll}
\hline & $\begin{array}{l}\text { Achievers } \\
n=28(\%)\end{array}$ & $\begin{array}{l}\text { Non-achievers } \\
n=29\end{array}$ \\
\hline $\begin{array}{lll}\text { No shunt }(\mathrm{n}=9) \\
\text { Shunt no revisions }(\mathrm{n}=16)\end{array}$ & $8(89)$ & 1 \\
$\begin{array}{l}\text { Shunt revised in infancy only } \\
(\mathrm{n}=10)\end{array}$ & $5(50)$ & 5 \\
$\begin{array}{l}\text { Shunt revised after age 2 }(\mathrm{n}=22) \\
\chi^{2} \text { for trend } \mathrm{p}<0.001 .\end{array}$ & $4(18)$ & 18 \\
\hline
\end{tabular}

\section{Subjects and methods}

The present review of the 57 survivors was carried out in 1997 by GMH using postal questionnaire and telephone. Information was obtained on place of residence, marriage, partnership, and child bearing; walking and use of wheelchair and car; occupation and employment; health, medication, other treatment, and hospital admissions. Data were also collected on the help needed from family and social services. Additional data were used from the researcher's own records of previous reviews and of examinations carried out at Addenbrooke's Hospital.

For the purpose of this study the main outcome measure consisted of three "achievements": independent living, driving a car, and having a job. These definitions need clarification.

INDEPENDENT LIVING

This was defined as living without supervision out in the community, coping independently with housekeeping and all personal needs and transport. It does not mean just personal independence in a sheltered environment where memories can be jogged, mistakes rectified, inaccessible pressure areas tended, and transport provided.

DRIVING A CAR

Driving was defined as habitual driving. It did not include merely passing the driving test as of those who had qualified, one third had given up driving, at least temporarily.

EMPLOYMENT

Employment was defined as doing a job on the open market in competition with the able bodied. It did not include sheltered employment.

Any survivor who had attained one or more of these achievements was defined as an "achiever".

Predictors of achievement were identified by univariate analysis, using a $\chi^{2}$ test. Shunt

Table 2 Achievements in 48 shunt treated patients with and without revisions

\begin{tabular}{llll}
\hline & $\begin{array}{l}\text { Shunts } \\
\text { unrevised } \\
n=16\end{array}$ & $\begin{array}{l}\text { Shunts } \\
\text { revised } \\
n=32\end{array}$ & Odds ratio (95\% CI) \\
\hline $\begin{array}{l}\text { Living independently } \\
\text { Sheltered or in care }\end{array}$ & 8 & 5 & $5.4(1.4 \text { to } 21.2)^{\star}$ \\
$\begin{array}{l}\text { Driving car } \\
\text { Not driving }\end{array}$ & 8 & 27 & $3.9(1.1 \text { to } 13.8)^{\star}$ \\
$\begin{array}{l}\text { Open employment } \\
\text { Sheltered employment or none }\end{array}$ & 9 & 8 & \\
Any achievement & 10 & 24 & $2.6(0.7$ to 1.0$)$ \\
No achievement & 11 & 6 & \\
\hline
\end{tabular}

${ }^{\star} \mathrm{p}<0.05 ;{ }^{\star \star} \mathrm{p}<0.01$. history (no revision $v$ revision) and IQ ( $\geqslant 80 v$ $<80$ ) were included in a multiple logistic regression analysis.

\section{Results}

Of the 117 original babies (50 male and 67 female) there were 57 survivors (26 male and 31 female) when reviewed in $1997 .{ }^{12}$ Sixty had died, 25 of these before their first birthday. The ages of the survivors ranged from 26 years and 6 months to 32 years and 9 months (mean age 30 years). Only 17 (30\%) of the survivors were still community walkers. Forty $(70 \%)$ had an $\mathrm{IQ} \geqslant 80$. Their disabilities ranged from none at all to total dependency with paralysis, incontinence, and blindness.

ACHIEVEMENT

Twenty eight of the survivors had at least one achievement and 29 had none.

Survivors without shunts $(n=9)$

Nine survivors had never had a shunt and eight of them lived independently in the community, five drove cars, and three were in open employment. They were all of normal intelligence and were generally less disabled than those who had shunts. Eight out of the nine without shunts were achievers compared with only 20 out of the 48 with shunts $(\mathrm{p}<0.05)$.

\section{Survivors with shunts $(n=48)$}

It is the achievement of these 48 survivors with shunts which forms the basis of this study. Sixteen had never had any operation on their shunt since its insertion during infancy. Eleven of these $16(69 \%)$ were achievers. By contrast, of the 32 who had had revisions of their shunt only nine $(28 \%)$ were achievers $(\mathrm{p}<0.01)$. Table 1 shows that the outcome was worst of all in those who had revisions after the age of 2 . Significantly fewer of those who had had a revision of shunt lived independently or drove a car (table 2).

SHUNT HISTORY

Of the 48 shunt treated survivors 47 had had the original shunt insertion during infancy at Addenbrooke's Hospital and one had had the shunt inserted at the age of 3 in Sheffield. The initial insertion of the shunt was performed when indicated by the baby's condition. In 20 the shunt was inserted during the first 21 days of life, in 13 this was done from the 22 nd to the 42nd day and in 15 it was after 42 days (6 weeks).

Thirty two patients had a total of 113 revisions of the shunt (mean 3.5, range 1-14). Ten of them had revisions only during infancy. The other 22 had revisions after the second birthday, 15 of them had revisions between 10 and 31 years of age. Seventeen of the 57 survivors had left the catchment area of Addenbrooke's Neurosurgical Department and six had had revisions carried out at other hospitals. The indications for revision are shown in table 3.

Elective revisions in asymptomatic patients were not performed at Addenbrooke's Hospital. A blocked shunt system was revised only in the presence of symptoms. Review of available 
Table 3 Number of operations and main reasons for 113 revisions of shunt in 32 patients (number of patients in parentheses)

\begin{tabular}{|c|c|c|c|c|}
\hline & $\begin{array}{l}\text { No of revisions } \\
\text { in nine } \\
\text { achievers }\end{array}$ & $\begin{array}{l}\text { No of revisions } \\
\text { in } 23 \\
\text { non-achievers }\end{array}$ & Total revisions & \\
\hline Blocked shunt ${ }^{\star}$ & $14(8)$ & $54(18)$ & 68 & $60 \%$ \\
\hline Infection (ventriculitis, shunt infection, septicaemia) & $5(3)$ & $13(6)$ & 18 & $16 \%$ \\
\hline Detachment & $1(1)$ & $13(8)$ & 14 & $13 \%$ \\
\hline Other (extrusion 4 , leaking back 2 ) & - & $6(5)$ & 6 & $5 \%$ \\
\hline Not known & - & $7(6)$ & 7 & $6 \%$ \\
\hline Total operations & 20 & 93 & 113 & $100 \%$ \\
\hline
\end{tabular}

^Blocked shunts were not revised if patients were asymptomatic.

Table 4 Features associated with revisions of the CSF shunt in 48 patients

\begin{tabular}{lcccc}
\hline & $\begin{array}{l}\text { Shunt never } \\
\text { revised } \\
n=16(\%)\end{array}$ & $\begin{array}{l}\text { Shunt revised in } \\
\text { infancy only } \\
n=10(\%)\end{array}$ & $\begin{array}{l}\text { Shunt revised } \\
\text { after age 2 } \\
n=22(\%)\end{array}$ & $\chi^{2}$ trend \\
\hline Achievers $(\mathrm{n}=20)$ & $11(69)$ & $5(50)$ & $4(18)$ & $\mathrm{p}<0.001$ \\
No episodes of raised intracranial pressure ( $\mathrm{n}=23)$ & $15(94)$ & $5(50)$ & $3(14)$ & $\mathrm{p}<0.001$ \\
No cranial visual defects $(\mathrm{n}=16)$ & $9(56)$ & $4(40)$ & $3(14)$ & $\mathrm{p}<0.05$ \\
Insertion of shunt after 6 weeks old ( $\mathrm{n}=15)$ & $9(56)$ & $4(40)$ & $2(9)$ & $\mathrm{p}<0.01$ \\
IQ $\geqslant 80(\mathrm{n}=31)$ & $12(75)$ & $7(70)$ & $12(55)$ & $\mathrm{NS}$ \\
Community walker $(\mathrm{n}=11)^{\star}$ & $4(25)$ & $5(50)$ & $2(9)$ & $\mathrm{p}<0.05$ \\
Mild or moderate disability $(\mathrm{n}=27) \dagger$ & $12(75)$ & $6(60)$ & $9(41)$ & $\mathrm{NS}$ \\
\hline
\end{tabular}

${ }^{\star}$ Community walker was defined as able to walk 50 metres or more.

†Mild or Moderate disability was defined as walker, or wheelchair with independent transfers, no severe cognitive handicap, toilet needs and pressure areas well managed.

Table 5 Predictors of achievement in 48 patients with shunts

\begin{tabular}{llll}
\hline & $\begin{array}{c}\text { With predictor } \\
\text { \% Achievers }\end{array}$ & $\begin{array}{c}\text { Without predictor } \\
\text { \% Achievers }\end{array}$ & Odds ratio (95\% CI) \\
\hline No revision of shunt $(\mathrm{n}=16)$ & $69(11 / 16)$ & $28(9 / 32)$ & $5.6(1.5 \text { to } 20.1)^{\star \star}$ \\
No episodes of raised intracranial pressure $(\mathrm{n}=23)$ & $61(14 / 23)$ & $24(6 / 25)$ & $4.9(1.4 \text { to } 17.0)^{\star \star}$ \\
No cranial visual defects $(\mathrm{n}=16)$ & $63(10 / 16)$ & $31(10 / 32)$ & $2.0(.5 \text { to } 7.4)^{\star}$ \\
$\mathrm{IQ} \geqslant 80(\mathrm{n}=31)$ & $55(17 / 31)$ & $18(3 / 17)$ & $5.7(1.3 \text { to } 23.8)^{\star}$ \\
Community walker $(\mathrm{n}=11)$ & $73(8 / 11)$ & $32(12 / 37)$ & $5.5(1.2 \text { to } 24.8)^{\star}$ \\
Mild or moderate disability $(\mathrm{n}=27)$ & $56(15 / 27)$ & $24(5 / 21)$ & $4.0(1.1 \text { to } 14.1)^{\star}$ \\
\hline
\end{tabular}

${ }^{\star} \mathrm{p}<0.05 ;{ }^{\star \star} \mathrm{p}<0.01$

Multiple logistic regression analysis showed that shunt history and IQ were independent predictors of achievement.

records showed that in 24 out of $32(75 \%)$ patients who had undergone revisions and in one of the $16(6 \%)$ without revisions, there had been clear evidence of raised intracranial pressure $(p<0.001)$. This included headache, neckache, irritability, vomiting, worsening of or the appearance of new eye signs, papilloedema, and drowsiness or alteration in consciousness.

Table 4 shows features associated with the shunt history. In the 16 patients who never required revision of the shunt there were significantly more achievers, fewer episodes of symptoms of raised intracranial pressure, and fewer cranial visual defects. The original insertion of the shunt was later in these patients. By comparison the 22 patients who continued to have revisions of their shunts after the age of 2 , showed poorer achievement, more episodes of symptomatically raised intracranial pressure, and more cranial visual defects. They had needed their original shunt insertion earlier.

CRANIAL VISUAL DEFECTS

Of the 48 patients with shunts, 32 had 36 cranial visual defects. These were squints in 25 , nystagmus in six, corneal opacity in three, and optic atrophy in two Two of these patients were totally blind. Corneal opacities were associated with neuropathic keratitis and in these patients an absent corneal reflex and a severe degree of hydrocephalus had been noted at birth. Cranial visual defects were also often associated with raised intracranial pressure. Of 25 patients in whom episodes of raised intracranial pressure had occurred 22 had visual defects compared with 11 of the 23 without raised intracranial pressure $(p<0.01)$. Cranial visual defects were also negatively correlated with achievement. There were 10 achievers in the 32 with cranial visual defects compared with 10 achievers in the 16 without $(\mathrm{p}<0.05)$.

PREDICTORS OF ACHIEVEMENT

Table 5 shows that patients with shunts were more likely to be achievers if they had had no revisions of the shunt, no episodes of raised intracranial pressure, no cranial visual defects, an $I Q \geqslant 80$, if they were community walkers, or if they had only mild or moderate disability. Multiple logistic regression analysis showed that shunt history (no revisions or revisions of shunt) and IQ were independent predictors of achievement. The odds ratio for no revisions of shunt, adjusted for IQ, was 5.5 (95\% CI 1.3-22.2); and for IQ, adjusted for shunt history, it was 5.5 (95\% CI 1.2-25.4).

\section{Discussion}

This is the first report of a complete cohort of patients with spina bifida followed up to the mean age of 30 by the same person. Because many of the worst affected patients had died the study is biased towards the better cases. As in Lorber's series ours shows survival of the fittest. ${ }^{2}{ }^{10}$ It differs from other studies in some important respects. Firstly, the study is com- 
munity rather than hospital based; only those whose shunts continue to cause problems still attend a neurosurgical department. Secondly, the mortality in the 1960 s was much higher than it is today resulting in a median survival time of 30 years. ${ }^{13}$ Communications were poorer than now, some families were socially deprived, and many lacked both telephone and transport.

Thirdly, the technology and experience in the management of hydrocephalus, as well as in other aspects of spina bifida, were less than they are today. Assessment of the patients was less complex and mainly clinical. Some neurosurgeons were reluctant to intervene without manifest need. In this cohort the initial insertion of the shunt and its revision were undertaken only when considered essential. In a thriving baby a modest increase in head circumference and a tense fontanelle were not indications for intervention; nor was poor school performance in a well child with an apparently blocked shunt. In most cases of revision of shunt there had to be clinical evidence of raised intracranial pressure.

Our data (table 1) suggest that revisions of the shunt performed in babies less than 2 years old were associated with a better outlook than when they were performed at a later age. Five out of $10(50 \%)$ of these babies became achievers. Experimental data on rats with hydrocephalus show a greater risk of raised intracranial pressure once the cranial sutures have fused. ${ }^{14}$ In the 22 subjects who had continued to need revisions of shunt after the age of 2 only four $(18 \%)$ were achievers. They had also needed earlier insertion of their original shunt. By six weeks of age 20 of the 22 had had their shunt inserted compared with only 13 of the other 26 babies (table 4). As the timing of the first insertion depended largely on the need manifested by the baby, could this be an early indication of future shunt dependency? It might perhaps reflect the influence of the basic intracranial anomaly on the long term outlook.

Most of the 16 survivors who never had a revision of their shunt remained well and symptom free despite the fact that the shunt may have been blocked, or partly blocked for many years. When the shunt was last examined by GMH, when the children had a mean age of 9 , ten of the 16 seemed to have a blocked shunt. ${ }^{9}$ By contrast a majority of those in the revised group had a working shunt. This suggests that the superiority in the later achievements noted in those who had never had a revision, was unlikely to be due to a perfectly functioning shunt. It also suggests that someone who has a blocked shunt but who remains asymptomatic, has less shunt dependency than another whose symptoms demand revision of the shunt. The concept of reduced shunt dependency is safer than that of arrested hydrocephalus. ${ }^{15-18}$ Four members of the cohort of 117 had had their shunts removed in the belief that they were not longer needed. One of them died suddenly soon afterwards. All the other three had to have a shunt inserted after intervals of 6-18 years.
As might have been predicted, this study shows that most achievers were of normal intelligence and without severe disability. What was not predicted was the association between revisions of shunt and lack of achievement, an association which was independent of IQ. Findings in other studies of the relation between IQ and revision of shunt are conflicting. ${ }^{19-21}$ Most revisions in this cohort followed episodes of raised intracranial pressure and it seems likely that poor achievement was related to these episodes. Could an episode of raised intracranial pressure have reduced motivation, drive, energy, or enterprise? Someone who achieves complete independence despite paralysis, sensory loss, and problems with mobility, incontinence, and pressure sores must be highly motivated to make the huge effort that such an achievement demands. Lack of motivation in some patients with spina bifida has been a problem long recognised by parents and professionals. ${ }^{22-25}$ It is possible that the association between shunt history and achievement could be due to some effect on motivation. Raised intracranial pressure, the operation of revision, or infection may have been responsible.

Infection of the CNS could have played a part in influencing achievement, but these cases were too few for statistical analysis. Infections had occurred in 10 of the 32 with a history of revision of shunt. These were shunt infections (seven), ventriculitis (two), and meningitis (one). The profound brain damage caused by ventriculitis in infancy has long been recognised ${ }^{6}{ }^{26}$ but only two of the nine babies so affected survived to the age of 30 . One of them was an achiever and one was not. One of the seven cases of shunt infection was also an achiever. An infection rate of 10 patients out of 48 with shunts $(21 \%)$ is remarkably low considering the time span of 30 years. ${ }^{26-28}$ Because infection of the CSF is a complication of operating on the shunt, the 16 patients with unrevised shunts were spared that particular risk.

In the whole original cohort of 117 babies there were 10 deaths from hydrocephalus and four cases of blindness. Timely revision of the shunt might have avoided a proportion of these deaths as well as preserving eyesight. In some cases considerable time elapsed between the onset of symptoms of raised intracranial pressure and operation. Headaches may be misconstrued as due to migraine, sinusitis, or stress. ${ }^{18}$ Attempting to live a normal life despite formidable handicaps must indeed be stressful. Palpation of the shunt is sometimes misleading. Brain scans may be delayed, and they may be inconclusive particularly if no previous scan is available for comparison. Deterioration in visual acuity and changes in eye signs are often missed. ${ }^{29-32}$ Delays in diagnosis and treatment, if not fatal, can increase damage to the brain and visual pathways. Not many doctors have experience of the shunt problems of patients with spina bifida. Parents on the other hand recognise symptoms, and are often both aware of the likely diagnosis and of the urgency of treatment. The benefits of direct contact with a 
neurosurgical unit for a patient with symptoms far outweigh the value of the annual attendance at the neurosurgical clinic when the patient is asymptomatic. Our results suggest that in patients with spina bifida, any symptoms indicating raised intracranial pressure should receive prompt and expert attention if serious long term consequences are to be avoided.

\section{Conclusion}

Achievement in adults with spina bifida relates not only to IQ but also to events in the history of the CSF shunt. The best outcome was seen in those who had not required a shunt, followed by those whose shunts were never revised. The worst outcome was seen in patients who had needed revisions of their shunts after the age of 2 years and in any who had had symptoms of raised intracranial pressure. It is possible that the poor achievement seen in some of these patients could be the effect of raised intracranial pressure on motivation.

We thank the patients who participated in this review and their doctors, the Association for Spina Bifida and Hydrocephalus for support, Drs Jo Poulton and Hugh Richards for their help and encouragement, and the Department of Neurosurgery at Addenbrooke's for permission to use their records.

1 Laurence K. Effect of early surgery for spina bifida on survival and quality of life. Lancet 1974;i:301-4.

2 Lorber J. Results of treatment of myelomeningocele. An analysis of 524 unselected cases with special reference to possible selection for treatment. Dev Med Child Neurol 1971;13:279-303.

3 Stark GD, Drummond M. Results of selective early operation in myelomeningocele. Arch Dis Child 1973;48 operation

4 Ames MD, Schut L. Results of treatment of 171 consecutive Ames MD, Schut L. Results of treatment of 171 consecutive
myelomeningoceles 1963-1968. Pediatrics 1972;50:46670 .

5 Smith GK, Smith ED. Selection for treatment in spina bifida cystica. BMf 1973;iv:189-97.

6 Hunt GM, Holmes AE. Some factors relating to intelligence in treated children with spina bifida cystica. Dev Med Child Neurol 1975;35:65-70.

7 Raimondi AJ, Soare P. Intellectual development in shunted hydrocephelic children. Am f Dis Child 1974;127:664-71.

8 Hunt GM, Lewin L, Gleave J, et al. Predictive factors in open myelomeningocele with special reference to sensory level. BMF 1973;iv:187-201.

9 Hunt GM. Spina bifida: implications for 100 children at school. Dev Med Child Neurol 1981;23:160-72.

10 Hunt GM. Open spina bifida: outcome for a complete cohort treated unselectively and followed into adulthood. Dev Med Child Neurol 1990;32:108-18.
11 Hunt GM, Poulton A. Open spina bifida: a complete cohort reviewed 25 years after closure. Dev Med Child Neurol 1995;37:19-29.

12 Hunt GM. Open spina bifida: a complete cohort reviewed at 30 years of age. Eur F Pediatr Surg 1997;7(suppl 1):30.

13 Hunt GM, Palmer C. Median survival time in open spina bifida. Dev Med Child Neurol 1997;39:568.

14 Kaiser G, Jones HC. Cerebrospinal fluid pressure in 10-day-old rats with congenital hydrocephalus. Eur 7 Pediatr Surg 1991;1(suppl 1):20-2.

15 Hemmer R, Böhn B. Once a shunt, always a shunt? Dev Med Child Neurol 1976;18(suppl 37):69-73.

16 Lorber J, Pucholt V. When is a shunt no longer necessary? An investigation of 300 patients with hydrocephalus and myelomeningocele: 11-22 year follow up. Zeitschrift für Kinderchirurgie 1981;34:327-29.

17 Guthkelch N. Aspects of the surgical management of myelomeningocele: a review. Dev Med Child Neurol 1986;28:525-32.

18 Tomlinson P, Sugarman ID. Complications with shunts in adults with spina bifida. $B M F$ 1995;311:286-7.

19 Halliwell M, Carr J, Pearson A. The intellectual and educational functioning with children with neural tube defects. Zeitschrift für Kinderchirurgie 1980;31:375-80.

20 Hurley AD, Bell S. Educational and vocational outcome of adults with spina bifida in relationship to neuropsychological testing. Eur 7 Pediatr Surg 1994;4(suppl 1):17-19.

21 Lumenta CB, Skotarczak V. Long term follow up in 233 patients with congenital hydrocephalus. Childs Nerv Syst 1995;11:173-5.

22 Anderson EM, Spain B. The child with spina bifida. London: Methuen, 1977

23 Carr J. Behavioural approach to problems of motivation in the spina bifida child. Zeitschrift für Kinderchirurgie 1982;37:184-6.

24 Tew B, Laurence KM, Jenkins V. Factors affecting employability among young adults with spina bifida and hydrocephalus. Zeitschrift für Kinderchirurgie 1990;45 suppl 1:34-6.

25 Iddon JL, Morgan DJR, Sahakian BJ. Cognitive dysfunction in patients with congenital hydrocephalus and spina bifida. Evidence for a dysexecutive syndrome? Eur 7 Pediatr Surg 1996;6(suppl 1):41.

26 McLone DG, Naidich TP. Myelomeningocele: outcome and late complications. In: Section of paediatric neurosurgery of the American Association of Neurological Surgeons, eds. Pediatric neurology. Philadelphia: Saunders. geons, eds.

27 Shurtleff DB, Foltz EL, Loeser JD. Hydrocephalus a definition of its progression and relationship to intellectual function diagnosis and complications. Am $\mathcal{F}$ Dis Child 1973;125:688-93.

28 Editorial. Cerebrospinal fluid shunt infections. Lancet 1989; i: $1304-5$.

29 Tew BJ, Laurence KM. Ocular defect, intellectual and motor performance in children with spina bifida cystica. Zeitschrift für Kinderchirurgie 1978;25:324-30.

30 Gaston H. Does the spina bifida clinic need an ophthalmologist? Z Kinderchir 1985;40(suppl 1):46-50.

31 Biglan AW. Ophthalmologic complications of meningomyelocele: a longitudinal study. Trans Am Ophthalmol Soc 1990;88:389-462.

32 Caines E, Dahl M. Ophthalmological findings in a prospective study of 22 children with spina bifida cystica. Eur $\mathcal{F}$ Pediatr Surg 1997; (suppl 1):S2-3. 